\title{
Research on the Impact of Incentive Mechanism on Performance in SMEs of China
}

\author{
Jun Feng1, a \\ ${ }^{1}$ Graduate School, Chinese Academy of Social Sciences, Beijing 102488, China \\ afengjunhr@126.com
}

Keywords: human resources, performance, incentives, the impact of incentives on performance

\begin{abstract}
The remarkable achievements have been achieved in China's economic development. SMEs play an important role. SMEs provide more than $80 \%$ of the jobs in cities and towns, the healthy development of is a major strategic task of the relationship between people' $\mathrm{s}$ livelihood and the social stability. However, the turnover rate of SMEs is high, and turnover is frequent. In the era of knowledge economy, talent is the core competitiveness of enterprises. How to attract people, retain people, motivate people, pool talents and realize enterprise development strategy, become the key issues that need to be solved urgently in the development of SMEs. In this paper, a questionnaire survey is conducted on Company F of SMEs to analyze its existing problems and propose solutions to them. This study shows that incentives have a positive impact on performance, can improve employee satisfaction, reduce employee turnover, bring better benefits for the enterprise.
\end{abstract}

\section{Introduction}

At present, China ranks second in the world in terms of total economic output. Experts from Chinese Academy of Social Sciences predict that China's total economy will catch up with the United States around 2034 and become the world's largest economy (Waldron, 2015). During the rapid economic development, SMEs have become one of the most active economies in our country. As of the end of 2015, there were over 20 million SMEs registered in the industrial and commercial sectors across the country. Taking industries as an example, small and medium-sized industrial enterprises above designated size accounted for $97.4 \%$ of the total industrial enterprises above designated size in China; $49.2 \%$ of taxation and $64.5 \%$ of profit (Munir et al., 2017). SMEs provide more than $80 \%$ of urban employment (Cui, 2011). Including indicators such as the number of enterprises, tax revenue, profitability and employment numbers from the perspective of SMEs, they have become an important foundation for the national economy of our country. The healthy development of SMEs is a major strategic task concerning the people's livelihood and social stability.

After nearly 40 years of reform and opening-up, SMEs are thriving, but their development is not optimistic. In the United States and Japan, the average life expectancy of SMEs is 8.2 years and 12.5 years respectively. The average life expectancy of SMEs in our country is only 2.5 years. (Akhtar et al., 2008). The number of SMEs in China is large, but the life cycle of enterprises is short, and the stronger is less.

There are many reasons that lead to the short life cycle of SMEs and the lack of sustainable development. One of the main reasons for this is the lack of scientific incentives to attract and retain core talents. Many SMEs lack advanced human resource concepts, lack of performance management and incentive mechanisms, fail to attract and retain qualified personnel, and undermine their vitality, competitiveness and creativity. They are difficult to gain a foothold in the fierce market competition.

\section{Literature Review}

There is a growing recognition that a primary source of competitive advantage derives from an organization's is human resources (Brewster et al., 2000). Baker \& Drucker (2003) said that talent is the source of all undertakings. The person is right, the matter is followed right. The career is naturally also become. Human resources are the most important resources of the organization, and other 
resources can be maximized, created value and realized wealth appreciation only through the integration of human resources.

The third technological revolution, which began in the 1940s and 1950s, brought mankind into the information age. It is realized that technology is a powerful driving force for social development. Compared with material resources such as capital, raw materials and energy, people's knowledge and ability are the core competitiveness.

Before and after the third technological revolution, new theories such as behavioral science emerged. In 1943 Maslow, an American psychologist, put forward a famous hierarchy of needs. He said that people have a hierarchy of five types of needs: physiological (food, water, warmth), Security (a secure income, knowing one has a job), social (friendships and camaraderie), self-esteem (respect), and self-actualization (becoming the person you believe you can become). According to Maslow's prepotency process principle, people are motivated first to satisfy each low-order need and then, in sequence, each of the higher-level needs (Maslow, 1943; Dessler, 1999).

Herzberg two-factor theory was put forward in 1959, he said the best way to motivate someone is to organize the job so that doing it provides the feedback and challenge that help satisfy the person's so-called higher-level need for things like accomplishment and challenging. Managers do this by enriching workers' jobs so that the jobs are more challenging, and by providing feedback and recognition - they make doing the job intrinsically motivating, in other words. Here, just doing the job provides the motivation. Among other things, Herzberg's theory makes the point that relying exclusively on financial incentives is risky. The employer should also provide the recognition and challenging work that most people desire (Herzberg, 1959).

The American economist, Schultz, proposed the theory of human capital in 1960, a theory known as the revolution in economic history. The theory of human capital reveals the mystery of the rapid growth of the American economy after world war ii. Human capital is the engine of growth, which has a higher contribution to economic growth. Human capital is increasingly recognized as the most important factor of production and the most important source of economic wealth and an engine of economic growth over time (Schultz, 1960).

The above statement shows that human resources are the most important resources. Whether it is national construction or enterprise development, high-quality talent is key to enhancing core competitiveness, achieve development goals and create a miracle of development. How to motivate people to produce better performance and how does motivation affect performance? The research results of existing literature have a good guiding role for this paper, and there are few researches on the impact of incentive mechanism on performance in SEMs. Based on the research results of others, this paper studies the impact of the incentive mechanism on performance in SEMs, and provides reference for the research on the impact of incentive on performance in SEMs.

\section{Research Design}

This paper studies the SMEs of science and technology company F, high turnover rate, employee satisfaction is low, the quality of enterprise performance is not ideal, hope that through using the advanced human resource management idea, establishing scientific incentive mechanism, can meet the needs of multi-level heart employees, improve the enthusiasm and creativity of human resources, reduce turnover and improve employee satisfaction, improve the competitiveness of the organization, through the scientific incentive mechanism to improve the organizational performance.

This paper aims at the practical problems encountered by SMEs company F: the high turnover rate, low employee satisfaction, unable to attract and retain talent and other issues. Through the use of Likert scale questionnaire design, proposed about organizational culture, mission, vision, values, atmosphere, interpersonal relationships, performance, motivation, training, career development and other different types of questions, the staff of the five answers: very satisfied, satisfied, general, not satisfied, very dissatisfied, respectively, recorded as 5,4,3,2,1 points, through staff attitude scores, to understand the feelings of the staff of the organization, ideas, opinions, satisfaction, etc.. The purpose is to find business problems; through statistical methods to identify the main problems; by analyzing 
the main issues, put forward the solution; through the comparison before and after the implementation of the program to study the impact of the incentive mechanism on performance.

\section{Analysis and Results}

The Meaning of Human Resource Development and Management. Human resources are the people who make up the workforce of an organization, business sector, or economy. Human Capital is sometimes used synonymously with Human Resources, although human capital typically refers to a narrower view. The development and management of human resources are the two main aspects of human resources. Human resources management is commonly recognized as the methods to maximize employees' performance in service of an employer's strategic objectives. Traditionally, human resources management focuses on employee-benefits design, employee recruitment, training and development, performance appraisal, rewarding, organizational change and industrial relations. However, due to globalization, company consolidation and technological advances in recent years, human resources management turns to focus on strategic initiatives like mergers and acquisitions, talent management, succession planning, industrial and labor relations. Scientifically combining the development and management of human resources may ensure an organization or an enterprise to perform better in talents attraction, retention, evaluation, motivation and gathering, to enhance the core competitiveness and innovation capabilities, as well as to achieve the vision and strategic objectives.

The Problems and Causes of Human Resource Management in SMEs. SMEs generally refer to enterprises with no more than 500 employees. Through the investigation of small and mediumsized technology company $\mathrm{F}$, we found that the main problems existing in the enterprise are as follows: human resources management did not rise to a strategic level, there were no people-oriented; enterprise lack cohesion; employees turnover rate is high; employees' satisfaction with enterprise is low; lack of scientific performance management system, the performance of employees cannot be objectively assessed; lack of scientific incentive mechanism, the contribution of employees cannot get a fair return. The analysis found that performance and incentive issues are major issues, because enterprise lacks the scientific performance management and incentive mechanisms. It prevents them from effectively attracting and retaining talent.

Building a Scientific Performance Management System. The construction of scientific performance management system, based on principles of fairness and justice, evaluates the performance level according to the completion of key performance indicators of employees: A (Excellent), B (Good), C (qualified), D (improvable), E (unqualified). Through performance feedback, guide employees to improve performance, enhance process control and improve performance. Through the application of performance results (rewards, career development, promotion, etc.), employees constantly improve their performance and strive to achieve performance goals. With performance results as the guidance, the enterprise provides support for the implementation of corporate strategic objectives, and provides a basis for employee motivation.

Establishing incentive mechanism to meet the needs of employees. William James, a psychologist at Harvard University in the United States, found in his research that employees who lack motivation can only play $20 \%$ to $30 \%$ of their ability; those who are fully motivated can exercise $80 \%$ to $90 \%$ of their ability, and a gap of $60 \%$ between lack of motivation and adequate motivation is the result of effective incentives. Enterprises should establish a comprehensive incentive mechanism based on material incentives (salary, benefits, bonuses, equity incentives, etc.), and spiritual motivation as the core (corporate mission and vision, corporate culture and values, integrity of managers, respect, employee care, effective communication, employee career development, etc.), fully stimulate the ability and potential of employees, and constantly improve the performance of individuals and organizations to achieve the strategic objectives of enterprise development.

The Impact of Incentive Mechanism on Performance. Incentive mechanism has a profound impact on employee performance. Employees see the close relationship between performance and incentive. Excellent performance enables employees to obtain comprehensive incentives, meet the material and spiritual needs of employees at multiple levels, and realize the staff's material needs of 
rich salaries, bonus returns, mentally recognized, respected, growing, promotion, self-realization of the expectations, and fully inspired the intrinsic enthusiasm and creativity, and continuously improve staff performance, formed a virtuous circle, to promote the better completion of the strategic development goals.

\section{Conclusion}

Performance is the goal to be achieved by the enterprise. Incentives are the goals to be achieved by the individual. Incentive mechanism based on the performance results, it closely links the business goals and personal goals, so that performance and incentives form a linkage mechanism: excellent performance will receive comprehensive incentive reward to meet the needs of employees; comprehensive, motivational rewards to meet employee needs motivate employees to create better performance.

Motivation is crucial to motivate employees' enthusiasm and creativity, and is crucial to improve employee performance. The incentive mechanism based on performance is the key to success in the fierce market competition. Performance is the basis of motivation; motivation is a powerful way to promote better performance of employees. The incentive increases, the employee's ability is fully played, the performance increases, and the incentive is positively correlated with the performance result.

The comprehensive incentive mechanism promotes the improvement of enterprise performance, and solves the problem of attracting talents, retaining talents, gathering talents and strengthening core competitiveness of the enterprises. The company F of SMEs, in the second half of 2017, through the establishment of scientific performance management system, the implementation of a comprehensive incentive mechanism based on performance, compared with the first half of 2017, employees' satisfaction increased by $30 \%$, the turnover rate dropped by $20 \%$, and work quality and efficiency were significantly improved.

\section{References}

[1] Akhtar, S., Ding, D. Z., \& Ge, G. L. (2008). Strategic HRM practices and their impact on company performance in Chinese enterprises. Human Resource Management, 47(1), 15-32.

[2] Baker, H., \& Drucker, P. F. (2003). The practice of management. Innovar Revista De Ciencias Administrativas Y Sociales, 50(33), 142-144.

[3] Brewster, C., Dowling, P., Grobler, P., Holland, P., \& Warnich, S. (2000). Contemporary issues in human resource management: gaining a competitive advantage. American Journal of Nephrology, 9(4), 291-9.

[4] Cui, P. F. (2011). The logistics management development strategy for SMEs in the national twelfth five-year plan. Enterprise Vitality.

[5] Herzberg, F., Mausner, B., \& Snyderman, B. (1959). The motivation to work (2nd ed.).

[6] Maslow, A. H. (1943). A theory of human motivation. Psychological Review, 50(1), 370-396.

[7] Munir, Q., Kok, S. C., Teplova, T., \& Li, T. (2017). Powerful CEOs, debt financing, and leasing in Chinese SMEs: evidence from threshold model. North American Journal of Economics \& Finance, 42, 487-503.

[8] Schultz, T. W. (1960). Capital formation by education. Journal of Political Economy, 68(6), 571583.

[9] Waldron, G. (2015). Is China feeling the chill? Indicators point to a business jet slowdown in the world's second-largest economy, but manufacturers are optimistic about the longer-term outlook. La Prensa Médica Mexicana, 39(3-4), 57-61. 